\title{
EDITORIAL
}

\section{Is the Malaria Elimination Target Achievable?}

\section{Abraham Haileamlak, MD, Professor of Pediatrics and Child Health}

Though preventable, malaria is still one of the major public health problems worldwide- mostly in low and middle income countries (1-4). In 2013, malaria killed over a billion people, mostly in sub-Saharan Africa (5). In 2015, there were over 200 million new cases and more than 400,000 malaria-related deaths around the globe (4).

Over three-quarter of the Ethiopian territory is malarious indicating $68 \%$ of the population are at risk $(6,7)$. According to the 2016 report, $27 \%$ of the population lives in high transmission areas while $41 \%$ lives in low transmission localities (8). The transmission of malaria in Ethiopia is unstable (9) and is seasonal following the end of rainy months.

Because of the integrated actions to combat malaria in the last decade and half, almost half of the world's nations are now malaria free (9). Similarly several countries have reduced malaria transmission to levels low enough to allow them to embark on, and in many cases achieve, elimination (10). Likewise, a notable progress was made to control and eliminate malaria from Ethiopia. The 2010-2015 National Strategic Plan for Malaria Prevention, Control and Elimination in Ethiopia was aimed to achieve malaria elimination within specific geographical areas with historically low malaria transmission and near zero malaria transmission in the remaining malarious areas of the country by 2015 . The specific strategies to achieve these goals were Community Empowerment and Mobilization, and Diagnosis and Case Management.

However, the target of elimination and zero transmission does not seem achievable because of several factors. Firstly, the required domestic and partners' funding might not sustain. Secondly, the absence of similar actions in neighboring countries could affect the malaria elimination target in Ethiopia negatively. One of the original articles in the current issue (September 2017) of EJHS examined the trend of malaria in high transmission districts. This issue (Vol. 27, No 5), the fifth regular issue for the year, contains one editorial, eleven original articles, one systematic review, one brief communication and one case report.

I invite readers to read through these articles and appreciate or utilize the contents. I also encourage readers to forward comments and suggestions to the editor or the corresponding authors.

\section{REFERENCES}

1. World Health Organization. World Malaria Report 2005. 20 Avenue Appia, 1211 Geneva 27, Switzerland. Available at: http://apps.who.int/iris/bitstream/10665/432 13/1/9241593199_eng.pdf.

2. Rowe K, Rowe Y, Snow W, et al. The burden of malaria mortality among African children in the year 2000. Int Journal of Epidemiol 2006; 35:691-704.

3. Ghebreyesus I, Deresa W, Written KH, et al. The epidemiology and Ecology of health and death in Ethiopia. Ethiop J Health Dev 2007; 21(2).

4. World Health Organization. Eliminating malaria, $\quad$ WHO/HTM/GMP/2016.3;20

Avenue Appia, 1211 Geneva 27, Switzerl and. Available at: http://www.who.int/about/licensing/copyrig ht_form/en/index.html.

5. World Health Organization. Global technical strategy for malaria 2016-2030; 20 Avenue Appia, 1211 Geneva 27, Switzerland. Available at: www.who.int/about/licensing/ copyright_form/en/index.html.

6. Epidemiology and distribution of malaria in Ethiopia. http://moodle.digitalcampus.org $/ \mathrm{mod} /$ page $/$ view.php?id=14803.

7. FDRE, MOH. Malaria prevention and control programs.

DOI: http://dx.doi.org/10.4314/ejhs.v27i5.1 
http://www.moh.gov.et/malaria?p_p_auth= Ws9d2X5o\&p_p_id=77\&p_p_lifecycle $=0$ $\&$ p_p_state $=$ maximized\&p_p_mode $=$ view \&_77_struts_action=\%2Fjournal_content_s earch\%2Fsearch.

8. World Health Organization. World Malaria Report 2016. Regional Profile. http://www.who.int/malaria/publications/wo rld-malaria-report-2016/WMR-2016regional-profiles.pdf?ua $=1$.

9. Nájera J, González-Silva M, Alonso, PL (2011) Some lessons for the future from the Global Malaria Eradication Programme
(1955-1969). PLoS Med 8: e1000412.J. NájeraM. González-SilvaAlonso, PL2011Some lessons for the future from the Global Malaria Eradication Programme (1955-1969). PLoS Med8e1000412

10. Roll Back Malaria (2008) Roll Back Malaria2008Global malaria action plan. Geneva: Roll Back Malaria Partnership. Available: http://rbm.who.int/gmap/gmap.pd Global malaria action plan. Geneva: Roll Back Malaria Partnership. Available: http://rbm.who.int/gmap/gmap.pd 